\title{
Measuring Perceived Anonymity: The Development of a Context Independent Instrument
}

\author{
Dwight M. Hite \\ Cameron University \\ Oklahoma
}

\author{
Troy Voelker \\ University of Houston \\ Clear Lake
}

\author{
Adrian Robertson \\ Montana State University \\ Billings
}

In order to assess relationships between perceptions of anonymity and behaviors, a context independent instrument is required for measuring the perceptions of anonymity held by individuals. To date, no such measurement instrument exists that has been shown to be reliable and valid. The authors employ a rigorous design methodology to develop, test, and substantiate a reliable and valid instrument for measuring perceptions of anonymity across different contexts. The PA measure presented is a five item Likert scale designed to measure perceptions of anonymity across multiple contexts. Results from two separate EFA pilot tests $(n=61$ and $n=60)$, a test-retest, and a CFA final test $(n=292)$ indicate that the PA measure has good internal consistency reliability $(\alpha=.82)$, test-retest reliability, factorial validity, and a single factor structure.

Keywords: anonymity, perceived anonymity, anonymity measure, anonymity perception

In today's "Information Age," true anonymity is difficult, if not impossible, to acquire. Whether people's actions are captured through video surveillance or cell phones, Internet service providers record Internet activity, or fingerprints and DNA samples are collected to identify individuals, it is extremely rare for complete anonymity to exist. Nonetheless, people often feel as though they are relatively anonymous when they engage in certain kinds of activities. For example, many individuals believe that they are anonymous when engaging in activity on the Internet (Ben-Ze'ev, 2003; Carvalheira \& Gomes, 2003; McKenna \& Bargh, 2000; Suler, 2004; Young, Griffin-Shelley, \& Cooper, 2000). Regardless of whether anonymity actually exists within such a context, individuals may perceive that they are anonymous, and it is this perception of anonymity that can influence their behavior.

Researchers have theorized about the relationships between anonymity and behavior for over a century (e.g. Le Bon, 1895/1995). The majority of research involving the influence of anonymity upon behaviors is experimental research in which anonymity is considered a dichotomous and objective phenomenon (see Postmes \& Spears, 1998). Treating anonymity in this manner does not account for the possibility of discrepancies between actual anonymity and individual perceptions of anonymity, nor does it consider the possibility of multiple levels of anonymity perception along a continuum from lower to higher levels of 
anonymity. It is likely that individual perceptions of anonymity explain behaviors more effectively than actual anonymity (Gavish \& Gerdes Jr., 1998; Scott, 1998) and that varying levels of perceptions correlate with varying levels of behaviors (Robbins \& Judge, 2011).

To assess relationships between perceptions of anonymity and behaviors, a context independent instrument is required for measuring the levels of anonymity perceived by individuals. Existing measures for anonymity tend to include only a single item or only a few items without evaluations of both validity and reliability, and oftentimes these measures are context specific. Hence, anonymity measures are usually not well evaluated and are often not functional in multiple contexts. This study seeks to fill this gap by developing and evaluating the validity and reliability of a measure for measuring perceptions of anonymity across various contexts.

\section{Theoretical Foundations}

\section{Traditional Definitions of Anonymity}

Anonymity is most often considered a dichotomous and objective phenomenon; that is, anonymity either exists, or it does not (Scott, 1998). In fact, much of the research involving anonymity does not include formal definitions of anonymity. Such studies simply assume that anonymity is dichotomous and objective (e.g. Piazza \& Bering, 2008), and that the definition of anonymity is implicitly understood. Such conceptualizations of anonymity inherently prohibit the inclusion and examination of levels of individual perceptions of anonymity in theoretical models.

Anonymity can be generally defined as the state of being unidentified or unknown. Wallace (1999) describes anonymity as "a form of nonidentifiability" and defines it as the "noncoordinatability of traits in a given respect" (p. 23). Marx (1999) defines anonymity as "one polar value of a broad dimension of identifiability versus nonidentifiability" (p. 100). Researchers within the social sciences oftentimes employ such definitions of anonymity.

Within communications research, definitions of anonymity generally focus upon the technical aspects of anonymity within communication systems. Gavish and Gerdes (1998) describe anonymity as "a composite of three types of anonymity - environmental, content-based, and procedural" (p. 306). Pinsonneault and Heppel (1997) define anonymity as "the inability of group members to identify the origin of messages they receive and the destination of messages they send" (p. 90). Definitions of anonymity within communications research tend to be context specific and often include technical and systemic aspects. 
Thus, the majority of traditional definitions for anonymity tend to focus upon an objective, or technical, conceptualization of anonymity. Such definitions often fail to consider the impact of individual perceptions of anonymity or account for a range of such perceptions. Furthermore, these definitions tend to be context-specific and do not lend themselves toward cross-disciplinary research.

\section{Anonymity and Behavioral Research}

Early scholars of social psychology (e.g. Le Bon, 1895/1995; Tarde, 1890/1921) theorized about the "group mind." These theorists suggested that anonymity, and the resulting loss of awareness of individual identity and breakdown of norms and values, leads to collective action within crowds (Postmes, Spears, \& Lea, 1999). From these early theories, a multitude of studies spawned that evaluated the relationships between anonymity and behaviors. Many of these studies utilized deindividuation theory as a theoretical foundation.

Deindividuation is a psychological state of decreased self-evaluation, causing anti-normative and disinhibited behavior (Zimbardo, 1969). Deindividuation theory suggests that anonymity induces deindividuation, and subsequently, anti-normative behavior. Deindividuation theory was introduced by Festinger, Pepitone, and Newcomb (1952), but it was Zimbardo (1969) who developed it within a theoretical framework. White (1977) considered the influence of anonymity and salient reference groups upon rates of socially inappropriate verbal behavior, indicating that deindividuating conditions were positively related to, and reference group salience was negatively related to, anti-normative behavior. Solomon, Solomon, Arnone, Maur, Reda, and Roth (1981) suggested that anonymous subjects are less helpful than identified subjects, and anonymous subjects are more likely to violate norms. A study by Rehm, Steinleitner, and Lilli (1987) found that lower identifiability led to an increase in anti-normative behavior, but these researchers suggest that both deindividuation and social identity theories explain such behaviors.

Although support for deindividuation theory exists, some researchers have sought alternative explanations. Reicher and Levine (1994) suggested that social identity theory provided more explanatory power than deindividuation theory with respect to the relationship between anonymity and behavior. Postmes and Spears (1998) conducted a meta-analysis of deindividuation theory, focusing upon the hypothesis that deindividuation causes anti-normative and disinhibited behavior, and found minimal support for deindividuation theory with respect to aggregated effect sizes. These researchers proposed the use of the Social Identity model of Deindividuating Effects (SIDE), which draws upon social identity and selfcategorization theories to provide alternative explanations for anonymity 
effects (Spears, Postmes, Lea, \& Watt, 2001). The SIDE model suggests that anonymity causes a loss of individual identity (i.e. deindividuation), but that a salient social identity emerges that reinforces situational group norms, and thus, leads to normative behaviors. While deindividuation theory asserts that anonymity results in deindividuation, and subsequently, anti-normative behavior, SIDE asserts that anonymity enhances reference group salience, encouraging normative behavior. Numerous studies provide support for SIDE within the domain of computer-mediated communication (CMC) (e.g. Barreto \& Ellemers, 2002; Kugihara, 2001; Lea, Spears, \& de Groot, 2001; Moral-Toranzo, Canto-Ortiz, \& Gomex-Jacinto, 2007; Postmes, Spears, \& Lea, 1998; Sassenberg \& Postmes, 2002).

In addition to the numerous studies implementing SIDE, other studies also examine the impact of anonymity upon behavior within CMC. For example, Connolly, Jessup, and Valacich (1990) conducted an experimental study to evaluate the influence of anonymity and evaluative tone upon the effectiveness of groups utilizing a group decision support system (GDSS), and Postmes and Lea (2000) conducted a meta-analysis to evaluate the assumption that anonymity is beneficial to groups for decision-making within GDSS. Additionally, Douglas and McGarty (2002) reported results of several studies in order to evaluate the inter-group characteristics of flaming (i.e. hostile or uninhibited) behavior within $\mathrm{CMC}$, as well as, the impact of identifiability upon flaming language, and Reinig and Mejias (2004) conducted an experimental study to examine flaming and comment criticalness in $\mathrm{CMC}$, and found that both culture and anonymity influence behaviors. Further, Muhlenfeld (2005) examined tendencies to provide socially desirable responses in anonymous online settings.

Furthermore, the relationship between anonymity and behavior has also been examined in other contexts. For instance, Fun-Yun Yu (2003) conducted an experimental study to examine the mediating effects of anonymity and proximity on group dynamics in an online synchronized team competition learning environment, and Silke (2003) conducted an archival study to examine the relationship between anonymity and aggression in violent interpersonal assaults. Studies have also been conducted that consider the influence of anonymity upon online sexual behavior (Carvalheira \& Gomes, 2003; Ross, Rosser, \& Stanton, 2004; Young, et al., 2000). Altogether, relationships between anonymity and behavior have been examined in numerous different contexts. However, little attention has been given to individual perceptions of anonymity within the extant literature. 


\section{Perceived Anonymity (PA)}

A few researchers have acknowledged the importance of perceptions of anonymity in explaining relationships between anonymity and behaviors. In a conceptual study designed to promote the continued development of anonymity as a research construct, Scott (1998) states, "Although certain processes and technologies may claim to be anonymous (or not), usage behavior likely depends far more on the extent to which communicators perceive anonymity" (p. 387). In their conceptual study, Gavish and Gerdes (1998) assert, “... a system's perceived level of anonymity may be more important than its actual anonymity" (p. 314). These researchers clearly refer to PA and advocate its development, while other researchers allude to the concept of PA without literally referring to it (e.g. Alonzo \& Aiken, 2004; McKenna \& Bargh, 2000), and others refer to it, but don't operationalized it (e.g. Kowalski, Morgan, \& Limber, 2012). Thus, although PA has not been fully assimilated into anonymity research, the concept is not entirely new.

While numerous definitions of anonymity exist, the definition of anonymity that is most applicable with respect to PA is the definition of social anonymity provided by Hayne and Rice (1997), who suggest that there are two types of anonymity: technical and social. These researchers assert that technical anonymity exists when "meaningful identifying information about others (or yourself) is removed from any material exchanged" and social anonymity exists when individuals "perceive others (and perhaps even oneself) to be deindividuated or unidentifiable" (p. 432). By focusing upon an internalized view of anonymity, PA is more concerned with the perception of oneself (rather than others) being unidentifiable. It is also important to note that anonymity should be considered a continuum, ranging from complete unidentifiability to complete identifiability, as suggested by Scott (1998). Perceptions of anonymity involve the perspectives of individuals regarding levels of identifiability. Hence, perceived anonymity is defined herein as the extent to which individuals perceive that their personal identity is unknown to others or that they are unidentifiable as an individual.

\section{Purpose of Study}

Despite the recognition of the importance of PA as a relevant construct within the social sciences, little has been done to formalize the measurement of PA. The few researchers who have attempted to capture PA often utilized scales with only 1-3 items, and provide little evidence of scale reliability or validity (e.g. Alonzo \& Aiken, 2004; Rains, 2007; Tsikerdekis, 2013). Thus, a reliable and valid instrument for measuring PA is needed for further work in the field. The purpose of this study is to 
develop an instrument for the measurement of PA and evaluate its reliability and validity.

During the extensive review of the extant literature, two key requirements of such a measure emerged. First, as noted by Scott (1998), any measure of PA must account for variation in perceptions of anonymity - PA is not a dichotomous and objective construct. Second, given the numerous different contexts in which anonymity may influence behavior (e.g. crowds, CMC, GDSS, etc.), an acceptable measure of PA should allow for flexibility across multiple contexts. Hence, we seek to develop a measure for PA that meets these requirements.

\section{Method and Results}

The methodology employed within this study involved a multi-stage process consisting of item and test case selection, expert review and pretest, pilot testing, test re-testing, and full testing of the measurement instrument. The methodology is based upon generally accepted principles of measurement design (e.g. Likert, 1967; Nunnally, 1967; Pedhazur \& Schmelkin, 1991; Shultz \& Whitney, 2005) and incorporates numerous evaluations of reliability and validity. This methodology provides a rigorous framework for the development of a reliable and valid measurement instrument.

Throughout the development of the PA measure, the reliability coefficient Cronbach's alpha served as the primary indicator of reliability. All exploratory factor analysis solutions were obtained utilizing maximum likelihood extraction methods and un-rotated solutions (and similar results were obtained utilizing alpha factoring extraction). During exploratory factor analyses in the pilot studies, factors with eigenvalues greater than one were extracted (Kaiser, 1960). Confirmatory factor analysis solutions executed in a third sample were obtained utilizing maximum likelihood parameter estimation (Thompson, 2004).

\section{Item and Test Case Selection}

During the literature review, the need for a relatively generic instrument that could be utilized across numerous different contexts was discovered. Thus, the PA instrument design incorporates a contextual scenario followed by items related to individual perceptions of anonymity. This design provides the instrument with flexibility, allowing modifications to the contextual scenario in order to customize the instrument towards a particular context. Given that the influence anonymity may have upon behaviors is dependent upon contextual factors, as suggested by Connolly, Jessup, and Valacich (1990), this is an important aspect of the instrument design. 
The initial item pool (shown in Table 1) for the PA instrument included ten items related to individual perceptions of anonymity, which were created based upon the definition of PA set forth herein, as well as the literature review. In order to evaluate the effectiveness of the contextual scenario design, four different scenarios served as test cases for the instrument. The test cases included "If I were to throw a small party for only my closest friends," "If I were to chat online with strangers," "If I were to answer my cell phone in a movie theater while a movie is playing," and "If I had to go to traffic court for a serious traffic violation and my name appeared in the newspaper as a result." These test cases were selected in order to simulate several contexts in which PA would likely differ.

\section{Expert Review and Pre-Test}

In order to evaluate the content validity of the PA measurement instrument, faculty members and doctoral students at a large Southern university critically reviewed both the individual items and the test case scenarios. These experts were selected based upon their knowledge in psychological, sociological, and social psychological concepts relative to anonymity and perceptions of anonymity. After being provided with the definition of perceived anonymity, they were asked to critically review the items and test cases and provide informed feedback regarding how well they represented the inherent aspects of perceived anonymity. Additionally, the instrument was pre-tested utilizing a group of individuals within an online gaming community. These activities provided important feedback, and this feedback prompted minor modifications to phrasing in some individual items.

\section{Pilot Testing}

Two separate pilot tests provided multiple tests of reliability and validity as well as refinement and enhancement of the instrument. The first pilot test (Pilot Test 1) involved administering the instrument to a sample of 61 undergraduate students, and utilized all four test case scenarios. The second pilot test (Pilot Test 2) involved administering the instrument to a separate sample of 60 undergraduate students, utilizing the 'small party' and 'chat online' scenarios. Student participation in pilot testing was voluntary. Data collected during both pilot tests were subjected to exploratory factor analysis in order to evaluate the unidimensionality and internal consistency of the instrument.

Pilot Test 1. The initial exploratory factor analysis results obtained from the Pilot Test 1 data set (shown in Table 1) indicated that the ten individual items included in the original item pool were not 
unidimensional. Two factors with eigenvalues greater than one were extracted. An analysis of individual item factor loadings, indicated that three items (i.e. 4, 9, and 10) exhibited relatively low factor loadings coupled with undesirable cross-loadings onto the second extracted factor. Therefore, these items were removed from the item pool in order to improve the unidimensionality of the instrument. Additionally, another item (i.e. 5) exhibited undesirable cross-loading with another construct under evaluation. This prompted the removal of this item from the instrument, reducing the instrument to six items.

Table 1

Pilot Test 1: Ten perceived anonymity items and maximum likelihood loadings $(n=61)$

\begin{tabular}{lcc} 
Perceived Anonymity Item & Factor 1 & Factor 2 \\
\hline $\begin{array}{l}\text { 1. It is difficult for others to identify me as an } \\
\text { individual }\end{array}$ & .63 & -.14 \\
$\begin{array}{l}\text { 2. I am confident that others do not know who } \\
\text { I am }\end{array}$ & .82 & -.02 \\
$\begin{array}{l}\text { 3. I believe that my personal identity remains } \\
\text { unknown to others }\end{array}$ & .83 & .14 \\
$\begin{array}{l}\text { 4. I choose if my personal identity is known } \\
\text { 5. My actions cannot be tracked back to my } \\
\text { personal identity }\end{array}$ & .56 & .72 \\
$\begin{array}{l}\text { 6. I am easily identified as an individual by } \\
\text { others (reverse coded) }\end{array}$ & .74 & -.05 \\
$\begin{array}{l}\text { 7. Others are likely to know who I am (reverse } \\
\text { coded) }\end{array}$ & .87 & -.27 \\
$\begin{array}{l}\text { 8. My personal identity is known by others } \\
\text { (reverse coded) }\end{array}$ & .77 & -.17 \\
$\begin{array}{l}\text { 9. I have no choice in others knowing my } \\
\text { personal identity (reverse coded) }\end{array}$ & .51 & .09 \\
$\begin{array}{l}\text { 10. It is not difficult to link my actions to my } \\
\text { personal identity (reverse coded) }\end{array}$ & .48 & .10 \\
\hline
\end{tabular}

The removal of items 4 and 9 is theoretically justified in that both these items relate to choice of anonymity. Item 4 states, "I choose if my personal identity is known" and Item 9 states, "I have no choice in others knowing my personal identity." These two items loaded heavily onto the second principle component, which is very likely associated with choice. The removal of items 5 and 10 is also theoretically justified in that these items can be interpreted as referring to different technical aspects associated with anonymity. Item 5 states, "My actions cannot be tracked back to my personal identity" and item 10 states, "It is not difficult to link my actions to my personal identity." Under various contextual conditions, these items 
can relate to differing technical facets. For example, in virtual contexts, these items can be interpreted as relating to the tracking of IP addresses or logging of keystrokes. Similarly, in 'real world' contexts these items can be interpreted as relating to surveillance methods such as wire tapping or video capturing.

The results obtained from exploratory factor analysis of the remaining six items (shown in Table 2) indicated unidimensionality of the instrument. Furthermore, the removal of the aforementioned items provided acceptable factor loadings for each individual item onto a single factor. The remaining six items explained $67.30 \%$ of total variance. The reliability coefficient for the resulting six-item instrument was 0.90 in Pilot Test 1.

Table 2

Pilot Test 1: Six perceived anonymity items and maximum likelihood loadings $(n=61)$

\begin{tabular}{lc} 
Perceived Anonymity Item & Factor 1 \\
\hline It is difficult for others to identify me as an individual & .63 \\
I am confident that others do not know who I am & .81 \\
I believe that my personal identity remains unknown to others & .78 \\
I am easily identified as an individual by others (reverse coded) & .76 \\
Others are likely to know who I am (reverse coded) & .90 \\
My personal identity is known by others (reverse coded) & .79
\end{tabular}

Pilot Test 2. The second pilot test included exploratory factor analysis of the refined six-item instrument obtained from Pilot Test 1, using the Pilot Test 2 sample data. The analysis results obtained (shown in Table 3) were very consistent with the findings of Pilot Test 1 . Only a single factor with an eigenvalue over one was extracted, and this factor explained $67.59 \%$ of total variance. Each individual item loaded well onto the single factor. These results confirmed the unidimensionality, of the instrument. The reliability coefficient for the instrument was 0.90 in Pilot Test 2.

Table 3

Pilot Test 2: Six perceived anonymity items and maximum likelihood loadings $(n=60)$

Perceived Anonymity Item $\quad$ Factor 1

It is difficult for others to identify me as an individual .68

I am confident that others do not know who I am $\quad .79$

I believe that my personal identity remains unknown to others $\quad .81$

I am easily identified as an individual by others (reverse coded) $\quad .68$

Others are likely to know who I am (reverse coded) $\quad .83$

My personal identity is known by others (reverse coded) $\quad .88$ 
One-way ANOVA results (Appendix A) indicated that significant mean differences in item responses existed between the test case scenarios utilized in Pilot Test 1, as well as Pilot Test 2. These results indicated that the levels of PA varied across the selected contextual scenarios. This demonstrated the ability of the instrument to differentiate between levels of PA across contexts.

\section{Test Re-Test Reliability}

A test re-test of the instrument provided additional evidence of reliability. The re-test involved administering the instrument to a subsample of 39 students taken from the sample utilized in Pilot Test 1. The 'chat online' scenario served as the test case for the re-test. Analysis of variance was utilized to evaluate mean differences in responses between the Pilot Test 1 sample and the re-test sub-sample. The time lapse between the test and re-test of the instrument was approximately four weeks. Oneway ANOVA results (Appendix A) indicated that there are no significant mean differences between the Pilot Test 1 sample and the re-test subsample, providing additional evidence of the reliability of the instrument.

\section{Final Instrument}

The full testing of the instrument involved the collection of responses from 292 participants in Massively Multiplayer Online Games (MMOGs). Respondents completed an online survey that collected information regarding numerous different aspects of online games and virtual environments. The PA instrument was included within this online survey. Internet discussion boards served as the medium through which participants could access the online survey. A total of 1265 individuals accessed the online survey, of which 298 completed the survey. Six responses were eliminated from the data set because of suspected extreme responding, leaving 292 usable responses, resulting in an effective response rate of $23 \%$. The demographic data collected from respondents indicated that it was a representative sample of online gamers.

The implementation within this context required a different contextual scenario. Thus, the full test participants responded to the individual items within the following context: "Please indicate your level of agreement or disagreement with each of the following statements, as they pertain to your real world identity while playing online games." The individual PA items were randomized with other items throughout the survey, in order to reduce consistency motif.

The full testing of the instrument included confirmatory factor analyses utilizing the full test data set. To allow for thorough testing, and because the full test data set was sufficiently large, the data set was randomly split 
into two sets (i.e. set A and set B). A confirmatory factor analysis was first conducted on Model A (shown in Figure 1) utilizing data set A.

Figure 1. Perceived anonymity (PA) confirmatory factor analysis model for data set $A(n=146)$. See Table 1 for the perceived anonymity items.

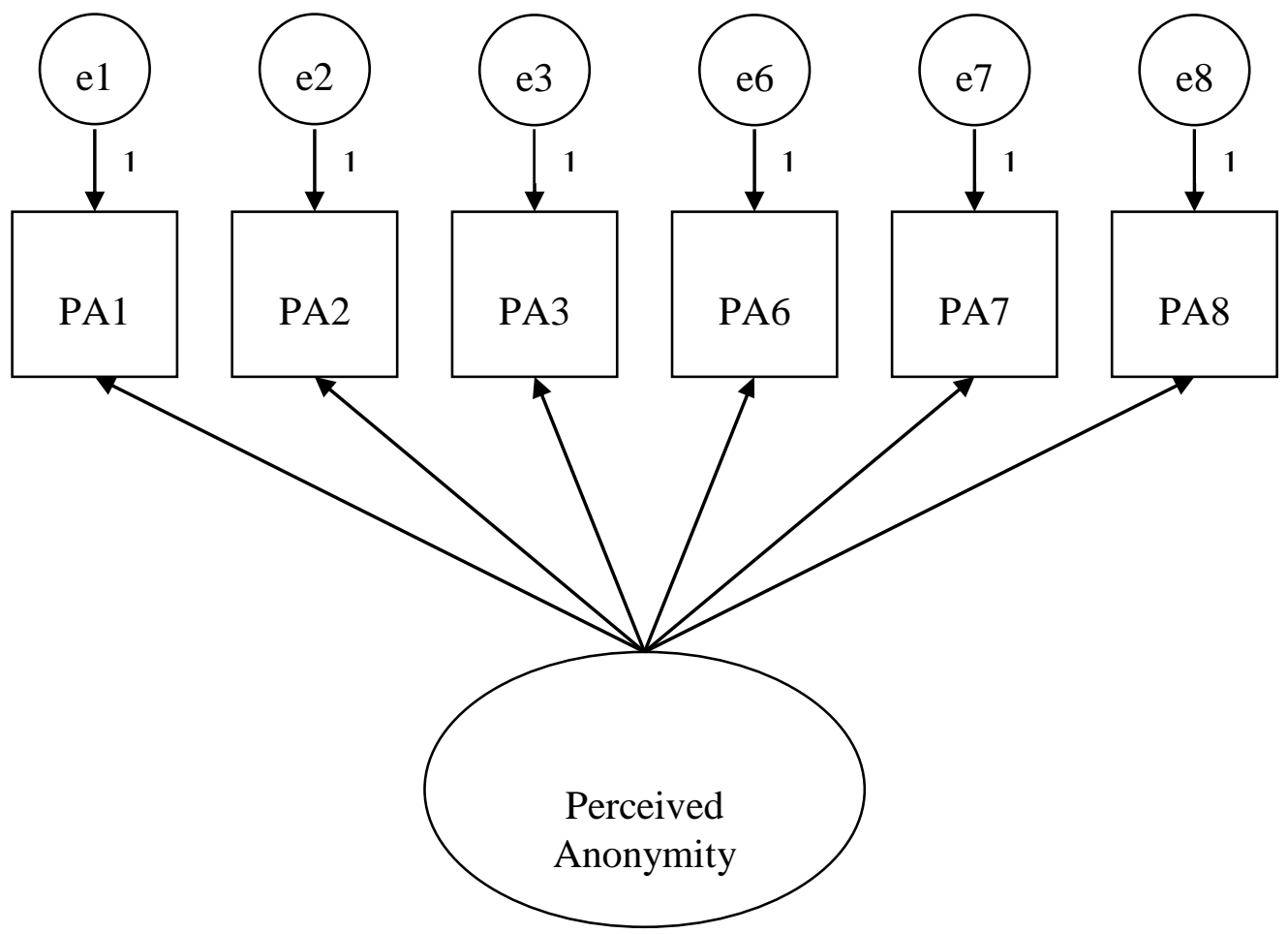

The results of this analysis indicate the model did not provide an adequate fit to the data, compared to the independence model. The comparative fit indices (e.g. NFI $=0.89, \mathrm{NNFI} / \mathrm{TLI}=0.85$, and $\mathrm{CFI}=0.91$ ) were below the generally accepted level of 0.95 (Schreiber et al., 2006); chi-square was 39.16(9) $(p<.001)$, and RMSEA was 0.15. The modification indices indicated that the error terms for items 1 and 6 were covariates; $\operatorname{cov}(\mathrm{e} 1, \mathrm{e} 6)=0.72$. Item 6 is a reverse coded version of item 1 , hence it is likely that this covariance indicates redundancy in the items.

Therefore, two different models were created, one which did not include item 1 (i.e. Model A1) and one that did not include item 6 (i.e. Model A2). Because these two models use different items, the underlying covariance structures are different and the two models cannot be compared utilizing fit indices. Therefore, the two models were evaluated utilizing reliability coefficients and factor loadings. Model A1 exhibited a higher reliability coefficient $(\alpha=.86)$ than did Model A2 $(\alpha=.83)$; item 6, which was retained in Model A1, exhibited a higher factor loading (.59) 
than did item 1 (.38), which was retained in Model A2. Based upon these results, Model A1 is the preferred model.

These results were particularly interesting because they suggest that the reverse coded item outperformed the positive coded item. While there is some evidence that reverse coded items can be problematic (e.g., Netemeyer, Bearden, \& Sharma 2003; Swain, Weathers, \& Niedrich 2008), this was not the case here. It is entirely possible that individuals are simply more comfortable making the evaluation associated with item 6 (i.e. I am easily identified as an individual by others) rather than the evaluation associated with item 1 (i.e. It is difficult for others to identify me as an individual). While individual perceptions of the evaluative tone of each of these statements may warrant further investigation, this is

Figure 2. Perceived Anonymity (PA) confirmatory factor analysis model for data set B $(n=146)$. See Table 1 for the perceived anonymity items. Standardized maximum likelihood parameter estimates shown. All parameter estimates are significant at the $p<.001$ level.

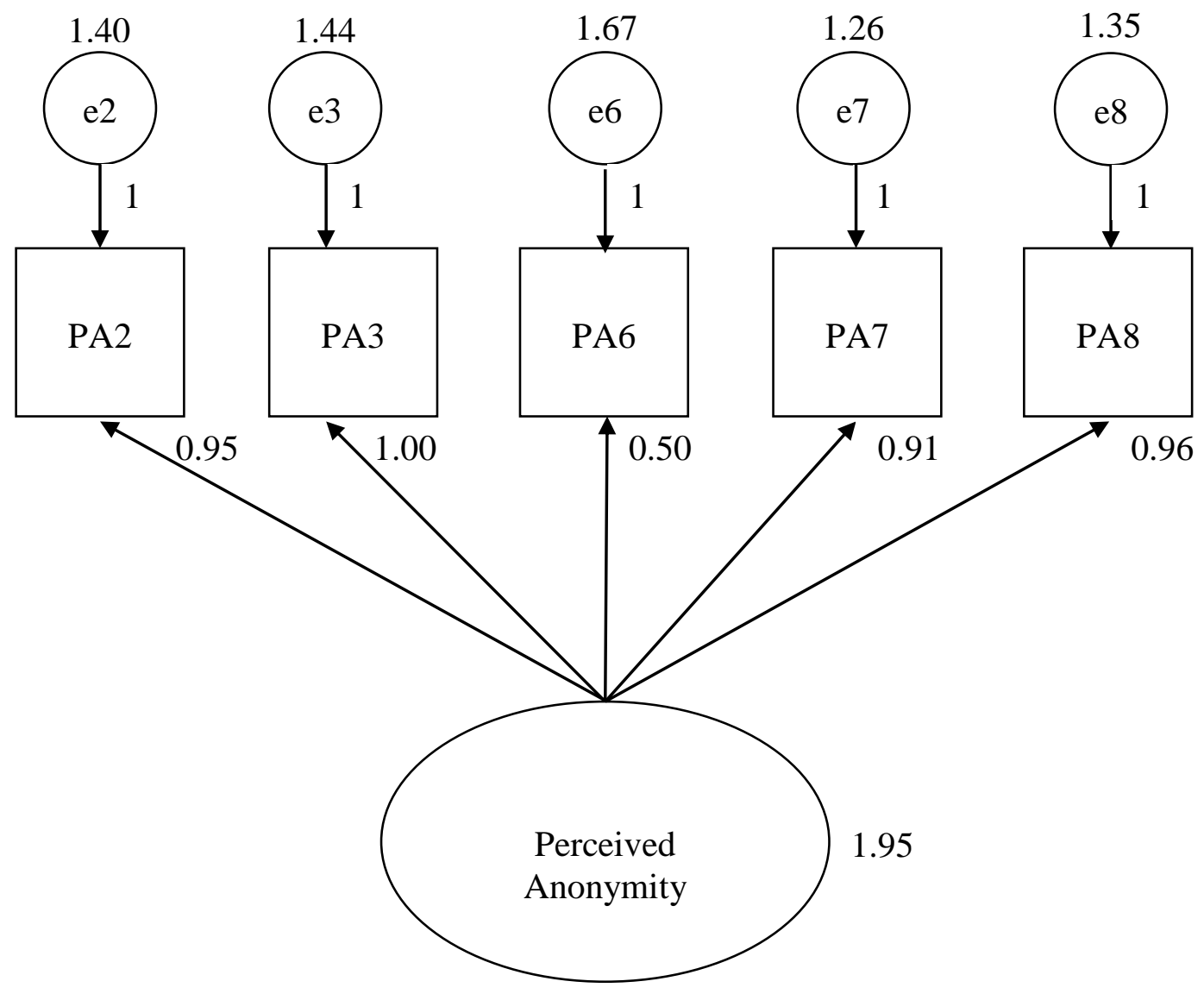


beyond the scope of this work. Model A1 was chosen as the preferred model, and item 1 was dropped from the instrument. The removal of item 1 is justified because the covariance between the error terms for items 1 and 6 suggested redundancy in these items.

Model A1 was renamed Model B (shown in Figure 2) for evaluating the model utilizing data set B (independent from data set A), and a separate confirmatory factor analysis was conducted. Model B demonstrated excellent comparative fit indices (e.g. NFI=0.98, NNFI/TLI $=1.00$, and $\mathrm{CFI}=1.00$ ), a chi-square of 4.32(5), and a RMSEA of 0.00. These results indicated that a single factor model including items $2,3,6,7$, and 8 provided an excellent fit to the data. Hence, the final PA measurement instrument consists of these five items.

\section{Discussion}

The results of the pilot tests and final instrument development provide convincing evidence for the reliability and validity of the new perceived anonymity measure. The finalized instrument is presented in Appendix B. Utilizing a rigorous methodology this study included evaluations of both reliability and validity.

The reliability of the instrument was evaluated throughout its development. The reliability coefficients obtained during pilot testing were at least 0.90 , and the reliability coefficient for the full test (data set B) was o.82. These reliability coefficients are well above generally accepted values, particularly for new measurement instruments (Nunnally, 1967). Furthermore, the test re-test results indicated that no significant differences existed, which demonstrates reliability. There is evidence that the PA instrument presented herein has sufficient reliability.

The validity of the instrument was also evaluated throughout the development of the instrument. The instrument's content validity was established during expert review and pre-testing. Construct validity was rudimentarily evaluated through the examination of perceptions of anonymity across various contexts in which levels of anonymity differ. The extraction of a single factor with an eigenvalue greater than one during pilot testing established unidimensionality, as did the confirmatory factor analyses results obtained during full testing. All of these evaluations, and subsequent results, provide evidence that the PA instrument is has sufficient validity.

The relationships between anonymity and behaviors are still not fully understood. This study represents a first step toward advancing the understanding of such relationships by providing researchers with a reliable and valid instrument for measuring perceptions of anonymity across multiple contexts. Given that such an instrument was previously 
non-existent within the body of knowledge, this study makes a meaningful contribution to the field.

\section{Limitations and Future Research}

The methodology employed within this study involved significant attempts to minimize limitations, yet they do exist. The use of convenient student samples during pilot testing may limit these results. However, the implementation and evaluation of the instrument utilizing a more realistic sample during the full test helps offset this limitation. Another limitation to this study is the use of self-reported data, particularly with respect to consistency motif, as described by Podsakoff and Organ (1986). Yet, the randomization of individual items throughout the online survey during the Full Test of the instrument minimized this effect. While limitations certainly exist within this study, diligent efforts were taken to minimize the impact of any such limitations.

Given that little research has considered perceptions of anonymity, there are numerous possibilities for future research. Additional research that tests the reliability and validity of the PA instrument, particularly within other contexts, would be beneficial. An interesting possibility is the replication of previous anonymity studies through which, instead of treating anonymity as a dichotomous and objective phenomenon, researchers could capture perceptions of anonymity. Such research could potentially provide significant insights. Longitudinal studies involving perceptions of anonymity are also promising. It would be very interesting to evaluate whether perceptions of anonymity degrade over time. More specifically, an evaluation of the relationship between perceptions of anonymity and time spent in virtual environments would likely prove to be interesting.

Author notes: Correspondence concerning this article should be addressed to Dwight Hite, School of Business, Cameron University, Lawton, OK; Tel: (580)581-7993; Email: dhite@cameron.edu

\section{References}

Alonzo, M., \& Aiken, M. (2004). Flaming in electronic communication. Decision Support Systems, 36, 205-213.

Barreto, M., \& Ellemers, N. (2002). The impact of anonymity and group identification on progroup behavior in computer-mediated groups. Small Group Research, 33, 590610.

Ben-Ze'ev, A. (2003). Privacy, emotional closeness, and openness in cyberspace. Computers in Human Behavior, 19, 451-467. 


\section{HITE, VOELKER, ROBERTSON}

Carvalheira, A., \& Gomes, F. A. (2003). Cybersex in Portuguese chatrooms: A study of sexual behaviors related to online sex. Journal of Sex \& Marital Therapy, 29, 345360.

Connolly, T., Jessup, L. M., \& Valacich, J. S. (1990). Effects of anonymity and evaluative tone on idea generation in computer-mediated groups. Management Science, 36, 689-703.

Douglas, K. M., \& McGarty, C. (2002). Internet identifiability and beyond: A model of the effects of identifiability on communicative behavior. Group Dynamics, 6, 17-26.

Festinger, L., Pepitone, A., \& Newcomb, T. (1952). Some consequences of deindividuation in a group. Journal of Abnormal and Social Psychology, 47, 382-389.

Fun-Yun Yu, R. (2003). The mediating effects of anonymity and proximity in an online synchronized competitive learning environment. Journal of Educational Computing Research, 29, 153-167.

Gavish, B., \& Gerdes Jr., J. H. (1998). Anonymous mechanisms in group decision support systems communication. Decision Support Systems, 23, 297-328.

Hayne, S. C., \& Rice, R. E. (1997). Attribution accuracy when using anonymity in group support systems. International Journal of Human-Computer Studies, 47, 429-452.

Kaiser, H. F. (1960). The application of electronic computers to factor analysis. Educational and Psychological Measurement, 20, 141-151.

Kowalski, R. M., Morgan, C. A., Limber, S. P., (2012). Traditional bullying as a potential warning sign of cyberbullying. School Psychology International, 33, 505-519.

Kugihara, N. (2001). Effects of aggressive behaviour and group size on collective escape in an emergency: A test between a social identity model and deindividuation theory. British Journal of Social Psychology, 40, 575-598.

Le Bon, G. (1895/1995). The crowd: A study of the popular mind. London: Transaction.

Lea, M., Spears, R. de Groot, D. (2001). Knowing me, knowing you: anonymity effects on social identity processes within groups. Personality and Social Psychology Bulletin, 27, 526-537.

Likert, R. (1967). The Human Organization: Its Management and Value. New York: McGraw-Hill.

Marx, G. T. (1999). What's in a name? Some reflections on the sociology of anonymity. Information Society, 15, 99-112.

McKenna, K. Y. A., \& Bargh, J. A. (2000). Plan 9 from cyberspace: The implications of the internet for personality and social psychology. Personality \& Social Psychology Review, 4, 57-75.

Moral-Toranzo, F., Canto-Ortiz, J., \& Gomez-Jacinto, L. (2007). Anonymity effects in computer-mediated communication in the case of minority influence. Computers in Human Behavior, 23, 1660-1674.

Muhlenfeld, H. (2005) Differences between 'talking about' and 'admitting' sensitive behavior in anonymous and non-anonymous we-based interviews. Computers in Human Behavior, 21. 993-1003.

Netemeyer, R G., William O. Bearden, W. O., \& Sharma, S. (2003), Scaling Procedures: Issues and Applications, Newbury Park, CA: Sage Publications, Inc.

Nunnally, J. (1967). Psychometric Theory. New York: McGraw-Hill.

Pedhazur, E. J., \& Schmelkin, L. P. (1991) Measurement, Design, and Analysis: An Integrated Approach. New York: Psychology Press.

Piazza, J., \& Bering, J. M. (2008). The effects of perceived anonymity on altruistic punishment. Evolutionary Psychology, 6, 487-501.

Pinsonneault, A., \& Heppel, N. (1997). Anonymity in group support systems research: A new conceptualization, measure, and contingency framework. Journal of Management Information Systems, 14, 89-108.

Podsakoff, P. M., \& Organ, D. W. (1986). Self-reports in organizational research: Problems and prospects. Journal of Management, 12, 531-545. 
Postmes, T., \& Lea, M. (2000). Social processes and group decision making: anonymity in group decision support systems. Ergonomics, 43, 1252-1274.

Postmes, T., \& Spears, R. (1998). Deindividuation and antinormative behavior: A metaanalysis. Psychological Bulletin, 123, 238-259.

Postmes, T., Spears, R., \& Lea, M. (1999). Social identity, normative content, and "deindividuation" in computer-mediated groups. In N. Ellemers \& R. Spears (Eds.), Social identity: Context, commitment, content. (pp. 164-183): Blackwell Science Ltd.

Postmes, T., Spears, R., \& Lea, M. (1998). Breaching or building social boundaries? Sideeffects of computer-mediated communication. Communication Research, 25, 689715 .

Rains, S. A., (2007). The impact of anonymity on perceptions of source credibility and influence in computer-mediated group communication. Communication Research, $34,100-125$.

Rehm, J. R., Steinleitner, M., \& Lilli, W. (1987). Wearing uniforms and aggression: A field experiment. European Journal of Social Psychology, 17, 357-360.

Reicher, S., \& Levine, M. (1994). On the consequences of deindividuation manipulations for the strategic communication of self: Identifiability and the presentation of social identity. European Journal of Social Psychology, 24, 511-524.

Reinig, B. A., \& Mejias, R. J. (2004). The efects of national culture and anonymity on flaming and criticalness in GSS-supported discussions. Small Group Research, 35, 698-723.

Robbins, S. P., \& Judge, T. A. (2011). Organizational Behavior. New Jersey: Prentice Hall.

Ross, M. W., Rosser, B. R. S., \& Stanton, J. (2004). Beliefs about cybersex and Internetmediated sex of Latino men who have Internet sex with men: Relationships with sexual practices in cybersex and in real life. AIDS Care, 16, 1002-1011.

Sassenberg, K., \& Postmes, T. (2002). Cognitive and strategic processes in small groups: Effects of anonymity of the self and anonymity of the group on social influence. British Journal of Social Psychology, 41, 463-480.

Schreiber, J. B., Stage, F. K., King, J., Nora, A., \& Barlow, E. A. (2006). Reporting Structural Equation Modeling and Confirmatory Factor Analysis Results: A Review. The Journal of Educational Research, 99, 323-337.

Shultz, K. S. \& Whitney, D. J. (2005). Measurement Theory in Action. Thousand Oaks, CA: Sage Publications.

Scott, C. R. (1998). Reveal or not to reveal: A theoretical model of anonymous communication. Communication Theory, 8, 381-407.

Silke, A. (2003). Deindividuation, anonymity, and violence: Findings from Northern Ireland. Journal of Social Psychology, 143, 493-499.

Solomon, H., Solomon, L. Z., Arnone, M. M., Maur, B. J., Reda, R. M., \& Roth, E. O. (1981). Anonymity and helping. Journal of Social Psychology, 113, 37-43.

Spears, R., Postmes, T., Lea, M., Watt, S. E. (2001). A SIDE view of social influence. In J. P. Forgas \& K. D. Williams (Eds.), Social influence: Direct and indirect processes. (pp. 331-350). Philedelphia, PA: Psychology Press.

Suler, J. (2004). The online disinhibition effect. CyberPsychology \& Behavior, 7, 321326.

Swain, S. D., Weathers, D., \& Niedrich, R. W. (2008), "Assessing Three Sources of Misresponse to Reversed Likert Items," Journal of Marketing Research, 45, 116-131.

Tarde, G. (1890/1921). Les lois de l'imitation [The laws of imitation]. Paris: Librairie Felix Alcan.

Thompson, B. (2004). Exploratory and Confirmatory Factor Analysis. Washington, DC: American Psychological Association. 


\section{HITE, VOELKER, ROBERTSON}

Tsikerdekis, M. (2013). The effects of perceived anonymity and anonymity states on conformity and groupthink in online communities: A Wikipedia study. Journal of the American Society for Information Science \& Technology, 64, 1001-1015.

Wallace, K. A. (1999). Anonymity. Ethics and Information Technology, 1, 23-35.

White, M. J. (1977). Counternormative behavior as influenced by deindividuating conditions and reference group salience. Journal of Social Psychology, 103, 75-90.

Young, K. S., Griffin-Shelley, E., \& Cooper, A. (2000). Online infidelity: A new dimension in couple relationships with implications for evaluation and treatment. Sexual Addiction \& Compulsivity, 7, 59-74.

Zimbardo, P. G. (1969). The human choice: Individuation, reason, and order versus deindividuation, impulse, and chaos. Nebraska Symposium on Motivation, 17, 237307. 


\section{Appendix A}

\section{ANOVA Results}

Supplemental Table

ANOVA analysis results summary

\begin{tabular}{l|ccc|ccc|ccc}
\hline & \multicolumn{3}{|c|}{$\begin{array}{c}\text { Pilot Test 1 } \\
(n=61)\end{array}$} & \multicolumn{3}{c|}{$\begin{array}{c}\text { Pilot Test 2 } \\
(n=60)\end{array}$} & \multicolumn{3}{c}{$\begin{array}{c}\text { Test-retest } \\
(n=39)\end{array}$} \\
\hline & $d f$ & $F$ & $p$ & $d f$ & $F$ & $p$ & $d f$ & $F$ & $p$ \\
\hline Item 1 & 3 & 12.20 & $<.001$ & 1 & 39.36 & $<.001$ & 1 & 1.79 & .18 \\
Item 2 & 3 & 36.11 & $<.001$ & 1 & 41.22 & $<.001$ & 1 & 0.47 & .49 \\
Item 3 & 3 & 25.45 & $<.001$ & 1 & 31.03 & $<.001$ & 1 & 0.74 & .39 \\
Item 6 & 3 & 22.74 & $<.001$ & 1 & 30.9 & $<.001$ & 1 & 1.12 & .29 \\
Item 7 & 3 & 42.62 & $<.001$ & 1 & 41.8 & $<.001$ & 1 & 1.13 & .29 \\
Item 8 & 3 & 25.54 & $<.001$ & 1 & 39.46 & $<.001$ & 1 & 0.11 & .74 \\
\hline
\end{tabular}

Note: Pilot Test 1 results compare the means for all four scenarios $(\mathrm{df}=3)$. Pilot Test 2 results compare the means of two scenarios $(\mathrm{df}=1)$. The testretest results compare the means over one month for one scenario $(\mathrm{df}=1)$.

\section{Appendix B}

\section{Final Perceived Anonymity Measurement Instrument}

Please indicate your level of agreement or disagreement with each of the following statements.

$<$ Insert contextual scenario (e.g. "When interacting with my work group...")>

I am confident that others do not know who I am

I believe that my personal identity remains unknown to others

I am easily identified as an individual by others (reverse coded)

Others are likely to know who I am (reverse coded)

My personal identity is known to others (reverse coded)

$<$ Responses range from strongly disagree to strongly agree on a 7-point Likert scale.> 